\title{
Geostatistical characterisation of soil moisture patterns in the Tarrawarra catchment
}

\author{
Andrew W. Western ${ }^{\mathrm{a}, *}$, Günter Blöschl ${ }^{\mathrm{b}}$, Rodger B. Grayson ${ }^{\mathrm{a}}$ \\ ${ }^{a}$ Centre for Environmental Applied Hydrology, Department of Civil and Environmental Hydrology. The University of Melbourne, \\ Melbourne, Australia \\ ${ }^{\mathrm{b}}$ Institut für Hydraulik, Gewässerkunde und Wasserwirtschaft, Technische Universität. Wien, Austria
}

Received 12 May 1997; revised 17 September 1997; accepted 2 October 1997

\begin{abstract}
Spatial soil moisture patterns have been measured in the 10.5 ha Tarrawarra catchment in temperate south-eastern Australia on 13 occasions using time domain reflectometry (TDR). Measurements are made on regular grids of between 500 and 2000 points for each occasion. The spatial correlation structure of these soil moisture patterns is analysed. Sample variograms are found to have a clear sill and a nugget. Exponential variogram models, including a nugget, fit the sample variograms closely. The geostatistical structure is found to evolve seasonally. High sills $\left(15-25(\% \mathrm{v} / \mathrm{v})^{2}\right)$ and low correlation lengths $(35-50 \mathrm{~m})$ are observed during the wet winter period. During the dry summer period sills are smaller $\left(5-15(\% \mathrm{v} / \mathrm{v})^{2}\right)$ and correlation lengths are longer $(50-60 \mathrm{~m})$. This seasonal evolution is explained on the basis of the importance of lateral redistribution of moisture during different seasons. Both a nugget effect due to measurement error and variability at small scales contribute to the variability at the $10 \mathrm{~m}$ scale, which is the smallest scale in most of the data sets. For one occasion four soil moisture patterns containing 514 samples were collected on $10 \times 20 \mathrm{~m}$ grids. These patterns are offset by $2 \mathrm{~m}$ in an easterly and/or a northerly direction. Variograms for these four patterns are similar which indicates that variograms used for the structural analysis are highly reliable. An analysis based on transects subsampled from typical summer and winter soil moisture patterns indicates that a substantial number of data points (more than about 300) are needed to obtain meaningful sample variograms. (C) 1998 Elsevier Science B.V.
\end{abstract}

Keywords: Soil moisture; Variogram; Correlation structure; Time domain reflectometry

\section{Introduction}

Soil moisture has a major influence on a range of hydrological processes including flooding (e.g. Kitanidis and Bras, 1980), erosion (e.g. Moore et al., 1988), solute transport and land-atmosphere interactions (Entekhabi et al., 1996), as well as a range of geomorphic (Beven and Kirkby, 1993) and pedogenic (Jenny, 1980) processes. Soil moisture is highly

\footnotetext{
* Corresponding author.
}

variable in space and a knowledge of the characteristics of that variability is important for understanding and predicting the above processes.

The spatial variability of soil moisture results from many processes acting over a range of scales. These include vertical and lateral redistribution over scales from centimetres to tens or hundreds of metres, and spatial variation in evapotranspiration and precipitation. These processes may be modulated by topography, soils, geology or vegetation. The resultant soil moisture pattern is likely to reflect these influences 
through variations at scales linked to the processes controlling the moisture pattern. One way of characterising this variability is by its geostatistical correlation structure in space. Quantitative estimates of this structure are required for a number of purposes including the interpolation of spatial patterns from point data, estimation of the average catchment soil moisture and for distributed hydrologic modelling in general.

The main structural parameters are the sill, the correlation length (or range) and the nugget. The sill is the level at which the variogram flattens out. If a sill exists, the process is stationary and the sill can be thought of as the spatial variance of two distantly separated points. The correlation length (or range) is a measure of the spatial continuity of the variable of interest. For an exponential variogram, the correlation length relates to the average distance of correlation while the range is the maximum distance over which spatial correlations are present. While the correlation length and the range contain very similar information, the numerical value of the range is three times the correlation length for an exponential variogram. Finally, the nugget relates to the variance between pairs of points separated by very small distances. More quantitative definitions are given later.

It is important here to recognise the difference between sample properties and the properties of the true underlying distribution (that is the population). Strictly speaking the sample variogram computed from the data gives the properties of the sample only. It is then statistical inference by fitting a smooth curve (a theoretical variogram) to the sample variogram that gives an estimate of the properties of the population. Whether the sill, range and nugget inferred from the sample are representative of the true values depends on the nature of the variability and the sampling regime.

Two sources of data have been used for previous geostatistical characterisation of soil moisture, namely remotely sensed data and field measurements. Remotely sensed soil moisture measurements from the Push Broom Microwave Radiometer (PBMR) (Schmugge and Jackson, 1996) and Electronically Steered Thinned Array Radiometer (ESTAR) are available. Both these sensors measure microwave emission (microwave brightness temperature) from the land surface passively. This microwave emission is influenced by a range of variables including soil moisture in the top $\sim 5 \mathrm{~cm}$ of the soil profile, vegetation type and water content, soil temperature, soil roughness and soil texture (Jackson and Le Vine, 1996). The remotely sensed signal is georeferenced and rasterised before analyses are conducted. Typical pixel sizes are $200 \times 200 \mathrm{~m}$ for airborne sensors.

Variograms of PBMR microwave brightness temperature from the 1992 Hydrologic Atmosphere Pilot Experiment (HAPEX-Sahel) in Niger show a sill and a range of $\sim 3500 \mathrm{~m}$ (Hollenbeck et al., 1996). PBMR data from the First ISLSCP Field Experiment (FIFE), conducted in Kansas, USA, had a similar variogram but with a range of $-4500 \mathrm{~m}$ (Schmugge and Jackson, 1996). Rodriguez-Iturbe et al. (1995) analysed the scaling behaviour of soil moisture data derived from ESTAR measurements of the subhumid Little Washita watershed in south-west Oklahoma, USA, during the Washita'92 experiment. They examined the variance reduction observed as $200 \times 200 \mathrm{~m}$ pixels were aggregated up to $1 \times 1 \mathrm{~km}$ and concluded that soil moisture exhibited scaling behaviour with a sealing exponent between -0.21 and -0.28 . While an implication of this is that the variogram does not reach a sill, it is not necessarily inconsistent with the behaviour of the HAPEX - Sahel and FIFE data above, since sills were not reached until scales of at least $3.5 \mathrm{~km}$.

One difficulty with interpreting geostatistical analyses of remotely sensed soil moisture is that it is unclear how the confounding factors influencing the remotely sensed signal impact on the analysis. There is no reason to assume that the scales of variation of factors such as soils and vegetation will be similar to the scales of variation of soil moisture. In some cases, such as the Washita'92 data, corrections for the influence of factors such as soil type and vegetation have been made when converting the remotely sensed signal to soil moisture. However, these corrections rely on the quality of both the algorithms used and the auxiliary data such as soil texture information and vegetation characteristics. Also, the sensors integrate the microwave signal over an area of the land surface, which means that the measurement process smooths out small-scale soil moisture variations. The integration inherent in the remotely sensed signal may increase the correlation lengths (Blöschl, 1996). The 
important point to recognise is that the geostatistical structure derived from remotely sensed data may be quite different from that of the soil moisture due to these problems. An alternative to using remotely sensed data is to use ground-based field measurements, which are a more direct measure of soil moisture.

A variety of results have been obtained from field sampling. A summary of results found in the literature is given in Table 1. Some of these studies have focused only on variability of soil moisture (e.g. Bell et al., 1980; Rajkai and Rydén, 1992) while others have explicitly considered spatial correlation. Some studies such as Schmugge and Jackson (1996), Charpentier and Groffman (1992) and Hills and Reynolds (1969) (their Windmill Hill site) have found little evidence of spatial correlation. These studies focused on near surface soil moisture which can be expected to be highly variable. Also for most hydrologic applications soil moisture over a deeper layer is of greater significance.

In contrast to the above results, a number of authors have found spatial correlations. Hills and Reynolds (1969) collected soil moisture measurements over a range of scales from the Chew Stoke catchment in the UK. While they did not consider spatial correlation structure explicitly, the variability increased significantly with scale, indicating that a degree of spatial correlation was present. Studies that explicitly considered spatial correlations include Warrick et al. (1990), Lehmann (1995) and Nyberg (1996). At the Maricopa Agricultural Centre in central Arizona, USA, Warrick et al. (1990) found ranges of 650 and $550 \mathrm{~m}$ and sills of 18 and 15.5, respectively on 31 May and 12 June 1988. Also in Arizona, Whitaker (1993) found ranges varying between 35 and $100 \mathrm{~m}$ and sills varying between 2 and $4.75(\% \mathrm{v} / \mathrm{v})^{2}$. Compared to both relatively wet (for an arid climate) and relatively dry conditions at the start and end of a drying period following a rain storm, Whitaker found shorter ranges and higher sills associated with intermediate soil moisture conditions half way through the drying period. In other words the transition period has the shortest ranges and highest sills. It is interesting to note that Whitaker had to combine her grid and transect data before any spatial correlation structure was evident. Lehmann (1995) found clear sills and a range of $300 \mathrm{~m}$ while Nyberg (1996) found a range of approximately $20 \mathrm{~m}$. Lehmann (1995) also examined seasonal variations in soil moisture variance and found an inverse relationship with mean moisture. Factors that vary between these catchments include climate, sampling resolution and catchment area. No doubt these differences are important in explaining the differences between the results.

Two comprehensive data sets from the R-5 experimental catchment in Oklahoma, USA, have been analysed by Loague (1992). The first consisted of soil moisture measurements at eight depths between 0.15 and $1.2 \mathrm{~m}$ at 4 sites on 90 occasions and measurements from a further 34 sites on 84 occasions. The second data set consisted of measurements from 247 sites (157 on a grid plus 2 transects) at a depth of $0.1 \mathrm{~m}$ between 20 and 25 November 1984. These data had a mean moisture of approximately $30 \%(\mathrm{v} / \mathrm{v})$. Spatial analyses were conducted for time-averaged topsoil and subsoil moisture from the first data set. No spatial correlation was apparent for the topsoil data and only limited correlation for the subsoil data. When individual sampling occasions were considered, similar spatial structures were evident for samples closely related in time and different structures characterised samples with a large separation in time. Loague (1992) suggested that no significant spatial structure was found in the second data set; however, the plotted variograms do exhibit some (poorly defined) structure.

Some of the field studies reviewed above have found spatial correlations, while others have not. Lack of spatial correlation in the data may be due to several possible reasons. First, the sampling spacing may have been greater than the range over which correlation existed. Second, sample sizes were possibly too small to reliably estimate spatial correlation. Third, measurement errors may have been larger than the variability of the soil moisture. In studies where evidence of spatial correlation has been found, ranges have varied by a factor of 30 for different field studies. Ranges estimated from remote sensing data are between 6 and 200 times larger than the field-based estimates. Again, part of the difference between individual studies appears to be related to different sampling scales, part to different measurement techniques and measurement depths, part to differences in climate, vegetation and topography between study areas and part to uncertainty in the sample variograms 


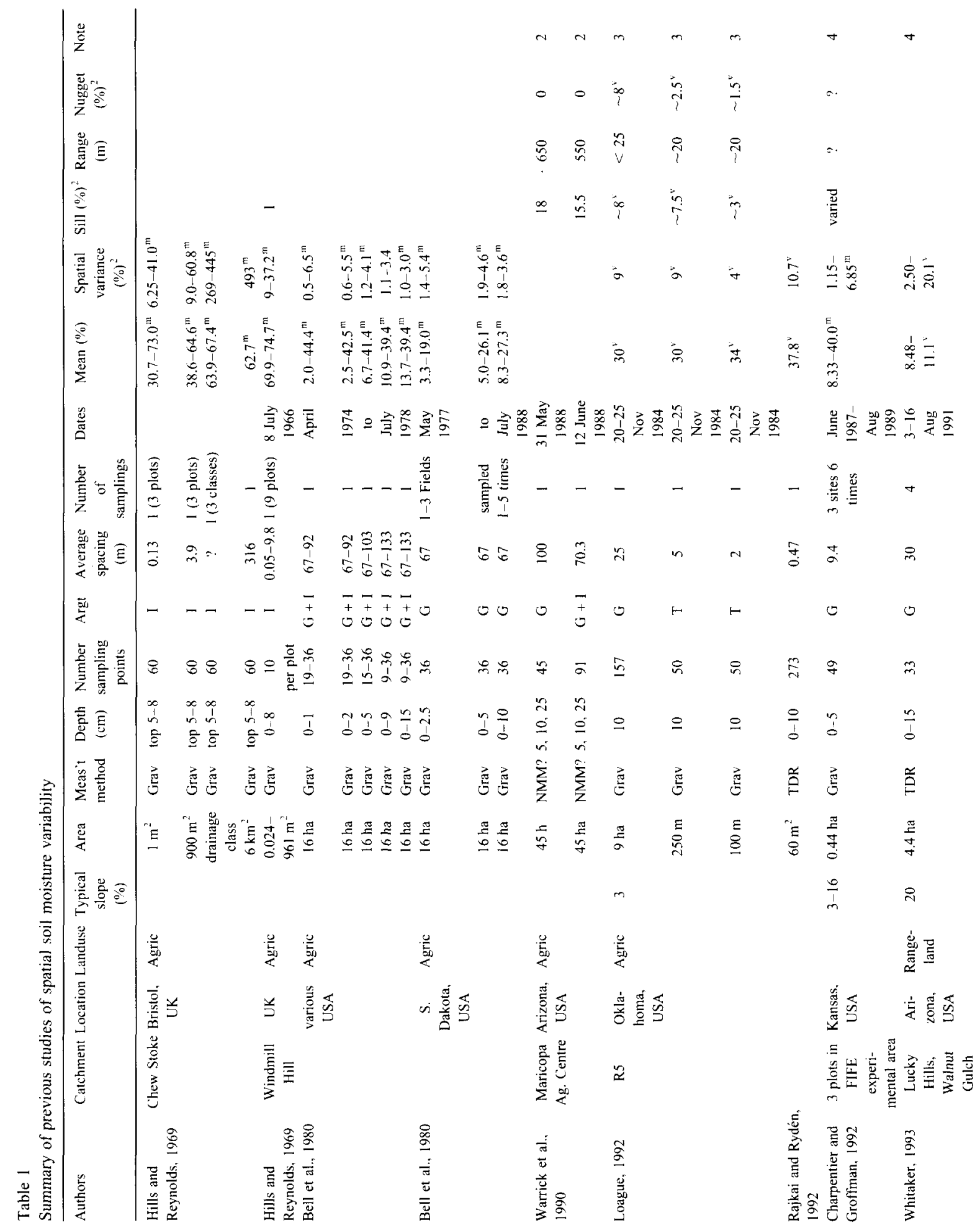




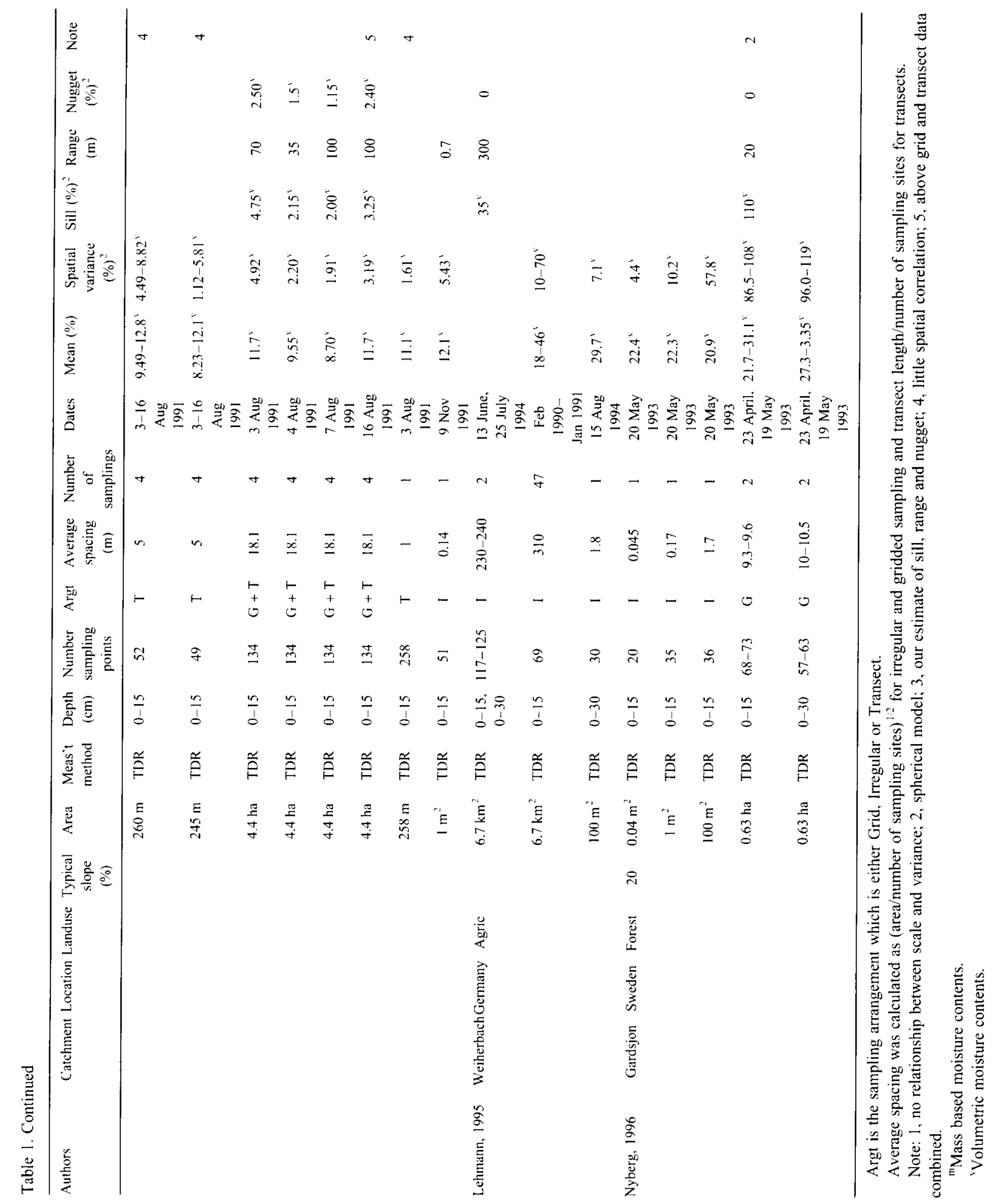


due to small sample sizes. For example, based on a resampling analysis, Warrick et al. (1990) report ranges that vary between 245 and $673 \mathrm{~m}$ when 45 data points are used, depending on the specific realisation. Indeed, the work to date on the geostatistical properties of soil moisture patterns is limited by the small sample sizes in the case of field studies and, in the case of remote sensing, by problems in isolating the part of the signal related to soil moisture. To the authors' knowledge, there have been no detailed studies on the seasonal evolution of the spatial structure of the soil moisture field. The aims of this paper are to analyse the geostatistical structure of the soil moisture field in the Tarrawarra catchment in southeastern Australia, based on a comprehensive data set, to analyse the seasonal changes in that structure and to examine the reliability of estimates of the geostatistical structure as a function of sample size.

\section{Study site and data set}

Data from the 10.5 ha Tarrawarra catchment in south-eastern Australia (Fig. 1) are used in this analysis. The catchment and data collection methods are described in detail by Western and Grayson (unpublished). Tarrawarra has a temperate climate and the average soil moisture levels are generally high during winter (April to September) and low during summer (October to March). Tarrawarra has pasture vegetation and is used for cattle grazing. The topography at Tarrawarra is undulating with maximum slopes of $14 \%$. The soils at Tarrawarra have a $20-35 \mathrm{~cm}$ deep A horizon, which is believed to be the hydrologically active zone from the perspective of lateral subsurface flow.

Thirteen spatial patterns of soil moisture have been collected in this catchment over a year. Eleven of these patterns consist of approximately 500 point measurements on a $10 \times 20 \mathrm{~m}$ grid, and two were more spatially detailed (approximately 1000 and 2000 points). The measurements were made over the top $30 \mathrm{~cm}$ of the soil profile using time domain reflectometry (TDR). The TDR probes are inserted using a hydraulic insertion system mounted on an all-terrain vehicle and sampling locations are determined using a position-fixing system with a resolution of $\pm 0.2 \mathrm{~m}$. Differences between gravimetric and TDR measurements collected in the field have a variance of $6.6(\% \mathrm{v} / \mathrm{v})^{2}$. An analysis of the magnitude of different error sources indicates that during normal operating conditions approximately half of this variance is due

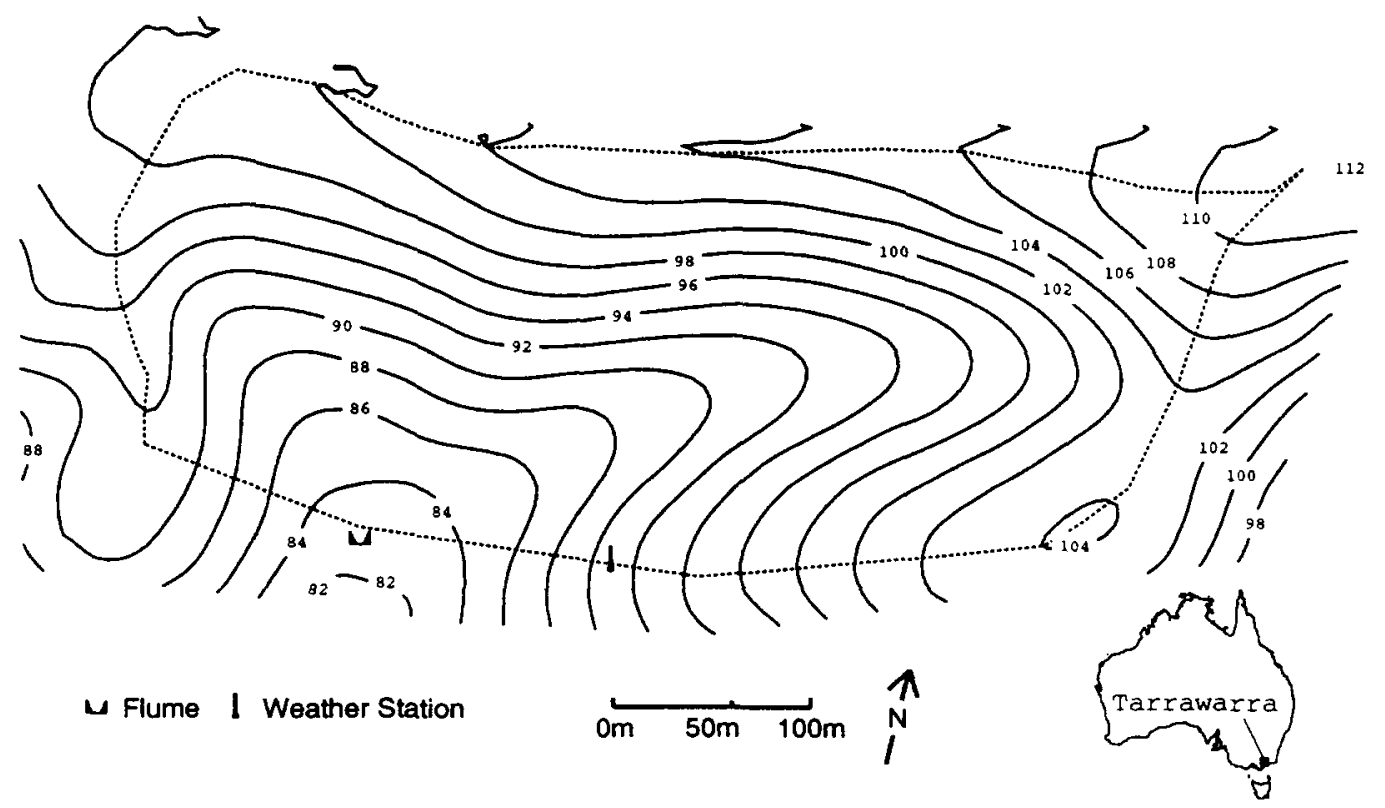

Fig. 1. The Tarrawarra catchment, Australia. The catchment boundary is shown as a dashed line. Topographic contours are shown as solid lines and elevations $(\mathrm{m})$ are given. 
Table 2

Summary of the 13 soil moisture patterns from Tarrawarra

\begin{tabular}{|c|c|c|c|c|c|c|c|c|}
\hline Date & $\begin{array}{l}\text { Antecedent } \\
\text { rainfall } \\
(10 \text { days, } \mathrm{mm})\end{array}$ & Run & Grid & Samples & $\begin{array}{l}\text { Mean } \\
(\% \mathrm{v} / \mathrm{v})\end{array}$ & $\begin{array}{l}\text { Variance } \\
(\% \mathrm{v} / \mathrm{v})^{2}\end{array}$ & $\begin{array}{l}\text { Coefficient } \\
\text { of variation }\end{array}$ & $\begin{array}{l}\text { Number } \\
\text { truncated }\end{array}$ \\
\hline 27 Sep 95 & 15.6 & 1 & $10 \times 20 \mathrm{~m}$ & 502 & 37.7 & 24.1 & 0.13 & 0 \\
\hline 14 Feb 96 & 58.4 & 2 & $10 \times 20 \mathrm{~m}$ & 498 & 26.2 & 10.6 & 0.12 & 0 \\
\hline 23 Feb 96 & 0 & 3 & $10 \times 20 \mathrm{~m}$ & 518 & 20.8 & 5.31 & 0.11 & 0 \\
\hline $28 \mathrm{Mar} 96$ & 7.0 & 4 & $10 \times 20 \mathrm{~m}$ & 501 & 23.9 & 7.06 & 0.11 & 0 \\
\hline 13 April 96 & 65.2 & 5 & $10 \times 20 \mathrm{~m}$ & 507 & 35.2 & 12.3 & 0.10 & 0 \\
\hline 22 Apr 96 & 70.8 & 6 & $10 \times 20 \mathrm{~m}$ & 513 & 40.5 & 14.6 & 0.09 & 0 \\
\hline 2 May 96 & 5.6 & 7 & $4 @ 10 \times 20 \mathrm{~m}^{\mathrm{a}}$ & 2056 & 41.4 & 19.4 & 0.11 & 1 \\
\hline $3 \mathrm{Jul} 96$ & 20.0 & 8 & $10 \times 20 \mathrm{~m}$ & 505 & 45.0 & 14.0 & 0.08 & 1 \\
\hline 2 Sep 96 & 22.2 & 9 & $10 \times 20 \mathrm{~m}$ & 515 & 48.5 & 13.9 & 0.08 & 35 \\
\hline 20 Sep 96 & 39.6 & 10 & $10 \times 20 \mathrm{~m}$ & 512 & 47.3 & 15.2 & 0.08 & 19 \\
\hline 25 Oct 96 & 14.6 & 11 & $10 \times 20 \mathrm{~m}$ & 490 & 35.0 & 19.2 & 0.13 & 0 \\
\hline 10 Nov 96 & 28.2 & 12 & $10 \times 10 \mathrm{~m}$ & 1008 & 29.3 & 10.8 & 0.11 & 0 \\
\hline 29 Nov 96 & 12 & 13 & $10 \times 20 \mathrm{~m}$ & 514 & 23.9 & 6.28 & 0.11 & 0 \\
\hline
\end{tabular}

${ }^{\text {a }}$ Soil moisture measurements were made on four grids of $10 \times 20 \mathrm{~m}$ offset by $2 \mathrm{~m}$ in an easterly and/or northerly direction.

to errors in the gravimetric measurements and half to errors in the TDR measurements. However, under extremely wet conditions when there is surface ponding or overland flow, some unrealistically high TDR measurements were obtained. To limit the effect of these high estimates on variance estimates, moisture values were truncated at a maximum moisture of $55 \%(\mathrm{v} / \mathrm{v})$, which is the maximum soil moisture observed in saturated areas without overland flow. This truncation affects 2 of the 13 moisture surveys.

Table 2 provides the dates, antecedent rainfall, number of sample points, mean, variance, coefficient of variation and number of truncated samples for each of the data sets used in the analysis. Examples of typical summer (23 February 1996) and winter (2 May 1996) soil moisture patterns are provided in Fig. 2. There are clear differences in the spatial patterns of soil moisture between summer and winter. In summer the landscape is dry and there is no clear spatial pattern. In winter the landscape is wet and the distribution of soil moisture is topographically controlled, with high moisture levels in the gullies. Lateral redistribution processes are important in winter but not in summer. These patterns are typical of the rest of the data set. The spatial patterns of soil moisture are explored in greater detail in Western et al. (unpublished), while Grayson et al. (1997) explore the existence of preferred states in the soil moisture distribution.
Fig. 3 shows histograms for six representative soil moisture surveys. The probability density functions are symmetric and close to Normal. The soil moisture variability is generally greater in the wet winter and small during the dry summer.

An additional data set has been collected on 25 October 1996 and is used for additional information on small-scale variability. This soil moisture sampling pattern consists of TDR measurements on a $2 \times 2 \mathrm{~m}$ grid over a $100 \times 68 \mathrm{~m}$ rectangle located over the upstream portion of the eastern drainage line. This gives a total of 1734 sampling points. The mean soil moisture for this data set is $40.3 \%(\mathrm{v} / \mathrm{v})$ and the variance is $23.8(\% \mathrm{v} / \mathrm{v})^{2}$.

\section{Method of analysis}

\subsection{Variogram analysis}

Variogram analysis was performed using standard geostatistical techniques (e.g. Journel and Huijbregts, 1978; Isaaks and Srivastava, 1989). Generally, omnidirectional variograms were used in this analysis and sample variograms were calculated using all pairs separated by lags up to $305 \mathrm{~m}$. This is about half of the maximum separation distance in the catchment. Pairs were grouped into lag "bins" and Eq. (1) was used to calculate the variogram for that bin. The mean lag of all the pairs in a particular bin was used as the 

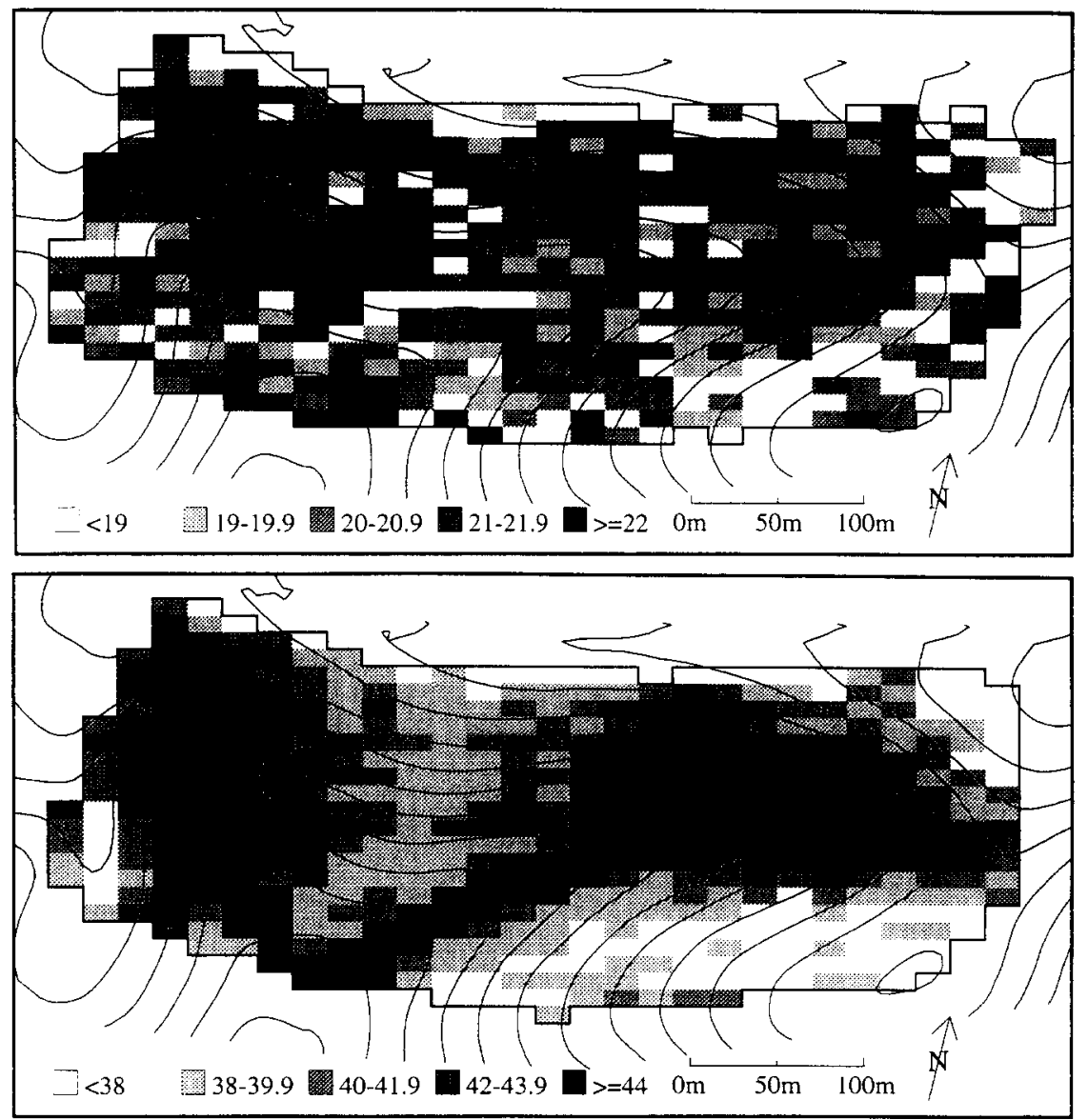

Fig. 2. Soil moisture patterns collected at Tarrawarra on (top) 23 February 1996 and (bottom) 2 May 1996. Note that each rectangle represents one point measurement of the average volumetric soild moisture in the top $30 \mathrm{~cm}$ of the soil profile.

representative lag for that bin. The sample variogram, $\gamma_{\mathrm{s}}(h)$, at a given lag, $h$, is:

$\gamma_{\mathrm{s}}(h)=\frac{1}{2 N(h)} \sum_{i, j}\left(\theta_{i}-\theta_{j}\right)^{2}$

where $N$ is the number of pairs, $\theta_{i}$ and $\theta_{j}$ is the soil moisture at points $i$ and $j$ respectively and the summation is conducted over all $i, j$ pairs in the lag bin.

Directional variograms are considered briefly and in those cases pairs were grouped into two angular bins, one in the northerly direction with an angular tolerance of $\pm 45^{\circ}$ and one in an easterly direction with the same tolerance. Then the directional variograms were calculated in the same way as the omnidirectional variograms.

Variogram models were fitted to the sample variograms by visual inspection using an interactive plotting program. Exponential models with a nugget (Eq. (2)) were used for all fitted variograms:

$\gamma_{\mathrm{e}}(h)=\sigma_{0}^{2}+\left(\sigma_{\infty}^{2}-\sigma_{0}^{2}\right)\left(1-\mathrm{e}^{-h / \gamma}\right)$

where $\gamma_{\mathrm{e}}(h)$ is the fitted variogram, $\sigma_{0}^{2}$ is the nugget, $\sigma_{\propto}^{2}$ is the sill and $\lambda$ is the correlation length. The practical range for the exponential model is $3 \lambda$. This is the point at which $\gamma$ reaches $95 \%$ of the sill. The quality of the variogram fits was characterised using the root mean square error (RMSE) calculated as:

$\operatorname{RMSE}=\left[\frac{\sum\left(\gamma_{\mathrm{e}}(h)-\gamma_{\mathrm{s}}(h)\right)^{2}}{n_{h}}\right]^{1 / 2}$ 

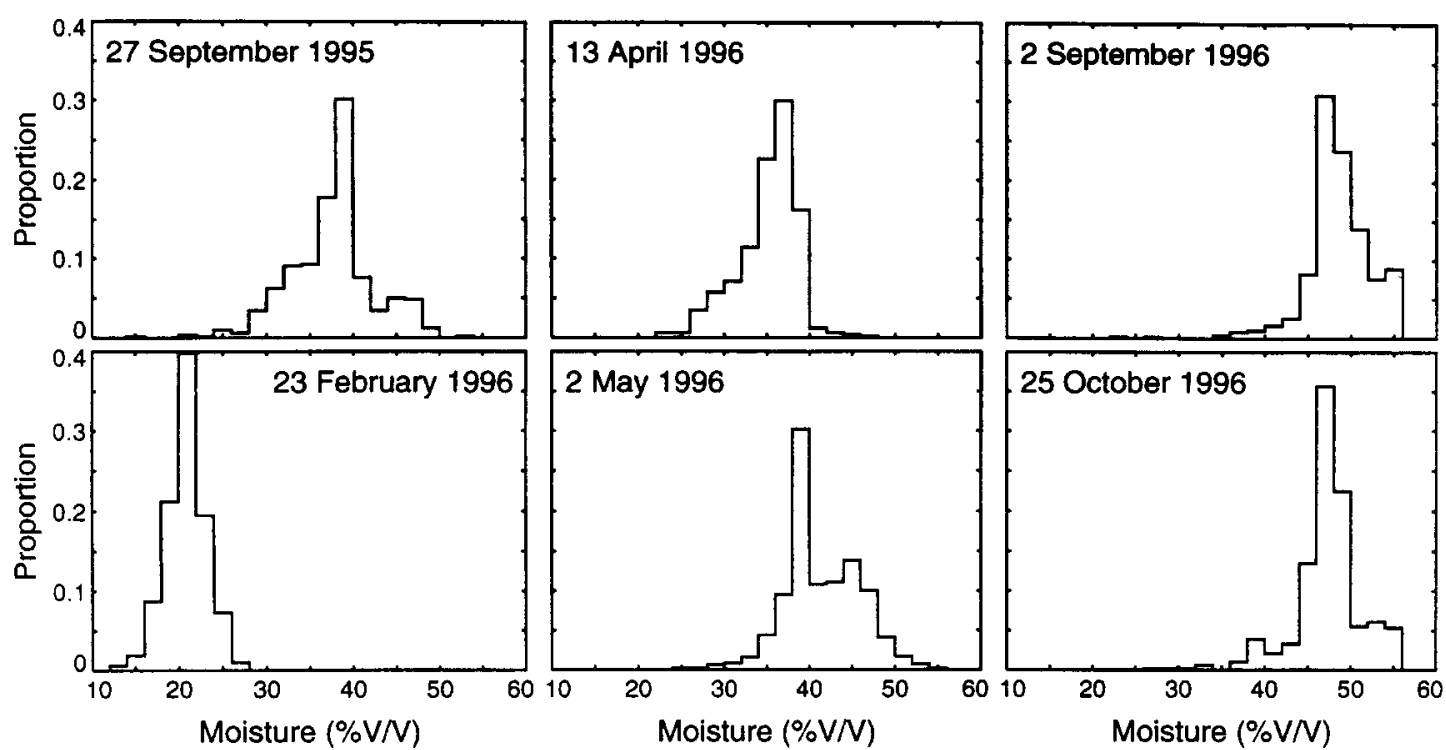

Fig. 3. Histograms of six representative soil moisture patterns from Tarrawarra.

where $n_{h}$ is the number of lag bins in the sample variogram.

\subsection{Sampling analvsis}

The aim of this part of the analysis was to examine how the reliability of the variogram increases with sample size. This was done by subsampling transects from the grid data. The rationale behind this analysis is that in most studies geostatistical parameters are estimated on the basis of small data sets (around 50 points, see Table 1). Here, the subsampling is based on transects because transects are a convenient means of sampling at both high resolution and large extent, thus providing a wide range of lags. Transects are also convenient from a field perspective. It should be noted that reliability of the variogram also depends on the sampling pattern (Warrick and Myers, 1987). However, this is beyond the scope of this paper.

In subsampling the following procedure was adopted. The pattern was divided into transects in the north-south and east-west directions. Very short transects (less than 10 points) were eliminated leaving 19 transects in the east-west direction and 21 transects in the north-south direction. Sixteen pairs of transects, each consisting of one transect in the northsouth direction and the other in an east-west direction were drawn randomly without replacement. Four cases were examined. The first involved 16 groups, each containing one pair of transects. For each group, one variogram was estimated which gave 16 variograms. The second case involved 8 groups, each containing 2 pairs of transects, which gave 8 variograms. Subsequent cases included 4 and 2 groups, each containing 4 and 8 pairs of transects. Sample variograms were calculated using Eq. (1). Data points were paired up only if they were on the same transect.

\section{Spatial variability and seasonal behaviour}

\subsection{Anisotropy}

Directional sample variograms were plotted for each data set to examine the anisotropy of the spatial correlation structure. Fig. 4 shows north-south, eastwest and omnidirectional variograms for 23 February 1996 and 2 May 1996. These are typical of other summer and winter variograms respectively. In summer the spatial correlation structure is isotropic. In winter there is anisotropy with a shorter range in the north-south direction than in the east-west direction. This anisotropy is related to the shape of the catchment. Short hillslopes in the north-south direction 

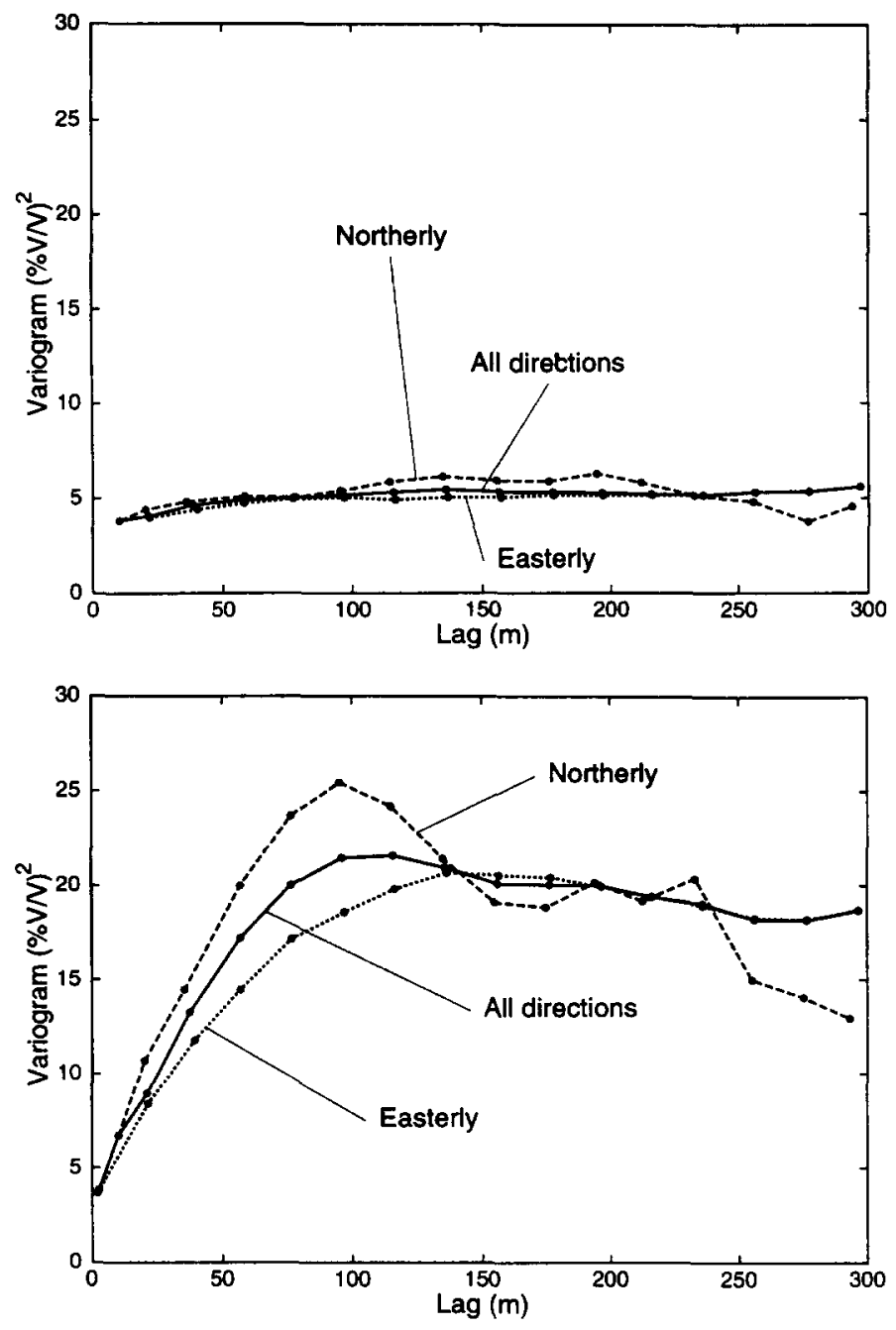

Fig. 4. North-south and east-west directional variograms and the omnidirectional variograms for Tarrawarra on (top) 23 February 1996 and (bottom) 2 May 1996.

and drainage lines that tend to run east-west mean the soil moisture pattern tends to be more continuous in the east-west direction when the soil moisture pattern is controlled by topography. This is the case in winter but not in summer.

For the remainder of the paper only omnidirectional variograms are considered for two reasons. First, the anisotropy observed is likely to be a function of the orientation of this particular catchment rather than a characteristic of the landscape as a whole. Second, topographic control is not the main focus of this paper and is examined elsewhere (Western et al., unpublished).

\subsection{Geostatistical structure and its seasonal evolution}

Fig. 5 shows variograms for six representative runs. Exponential variogram models with a nugget have been fitted to the data. Table 2 provides a summary of the fitted variogram parameters. The shape of the sample variograms is closely fitted by the exponential model. The RMSE is generally less than $0.8(\% \mathrm{v} / \mathrm{v})^{2}$, with only one RMSE exceeding $1(\% \mathrm{v} / \mathrm{v})^{2}$ (Table 3$)$. All the variograms indicate that the soil moisture field is stationary since they exhibit clear sills. The sills are 

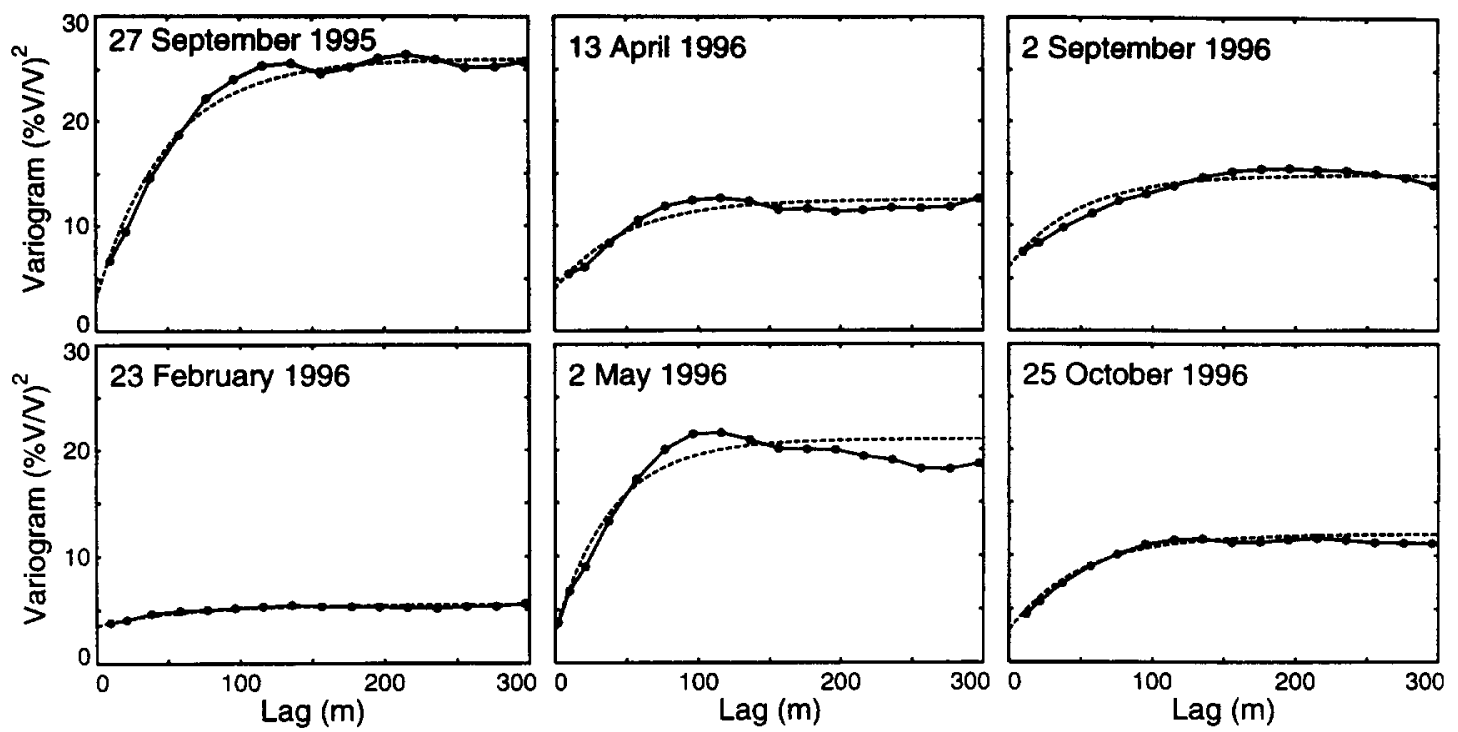

Fig. 5. Sample omnidirectional variograms (solid lines) for six representative soil moisture patterns from Tarrawarra. Exponential variograms (dashed lines) with a nugget have been fitted to the sample variograms.

close to the variance of the sample. Ranges for the variograms are well defined. It will be shown below that these variograms are based on sufficient data to be highly reliable.

The seasonal evolution of the geostatistical structure is detailed in Table 3 and Fig. 6. The sill (variance) varies between 5 and $25(\% \mathrm{v} / \mathrm{v})^{2}$ and follows a clear seasonal trend. This trend is related to the processes dominating the soil moisture pattern which are determined by the seasonal trend in mean soil moisture. In summer, when the soil is dry, the moisture is relatively uniform, hence the sill is low. This is because the soil moisture is being limited by the water retention properties of the soil (i.e. there is a strong soil moisture control on evapotranspiration) and lateral redistribution is unimportant. The existing variability is related to soil differences and possibly evapotranspiration differences due to varying

Table 3

Summary of the geostatistical structure of the 13 soil moisture patterns from Tarrawarra. The nugget, sill and correlation length are obtained from the fitted equation. The practical range is $3 \lambda$. The RMSE (Eq. (3)) is a measure of the quality of the fit of the exponential model with nugget

\begin{tabular}{|c|c|c|c|c|c|}
\hline Date & Run & $\begin{array}{l}\text { Nugget } \sigma_{0}^{2} \\
(\% \mathrm{v} / \mathrm{v})^{2}\end{array}$ & $\begin{array}{l}\text { Sill } \sigma_{x}^{2} \\
(\% v / v)^{2}\end{array}$ & $\begin{array}{l}\text { Correlation } \\
\text { length, } \lambda(\mathrm{m})\end{array}$ & $\begin{array}{l}\text { RMSE } \\
(\% \mathrm{v} / \mathrm{v})^{2}\end{array}$ \\
\hline 27 Sep 95 & 1 & 3.0 & 26.0 & 50 & 0.84 \\
\hline 14 Feb 96 & 2 & 6.0 & 11.0 & 60 & 0.50 \\
\hline 23 Feb 96 & 3 & 3.5 & 5.5 & 60 & 0.15 \\
\hline 28 Mar 96 & 4 & 4.0 & 7.5 & 60 & 0.18 \\
\hline 13 Apr 96 & 5 & 4.0 & 12.5 & 50 & 0.76 \\
\hline 22 Apr 96 & 6 & 3.0 & 15.5 & 35 & 0.74 \\
\hline 2 May 96 & 7 & 3.0 & 21.0 & 40 & 1.57 \\
\hline $3 \mathrm{Jul} 96$ & 8 & 6.0 & 15.0 & 50 & 0.64 \\
\hline 2 Sep 96 & 9 & 6.0 & 15.0 & 50 & 0.66 \\
\hline 20 Sep 96 & 10 & 5.0 & 16.0 & 45 & 0.85 \\
\hline 25 Oct 96 & 11 & 5.0 & 20.0 & 40 & 0.68 \\
\hline 10 Nov 96 & 12 & 3.0 & 12.0 & 50 & 0.47 \\
\hline 29 Nov 96 & 13 & 2.5 & 7.0 & 60 & 0.35 \\
\hline
\end{tabular}



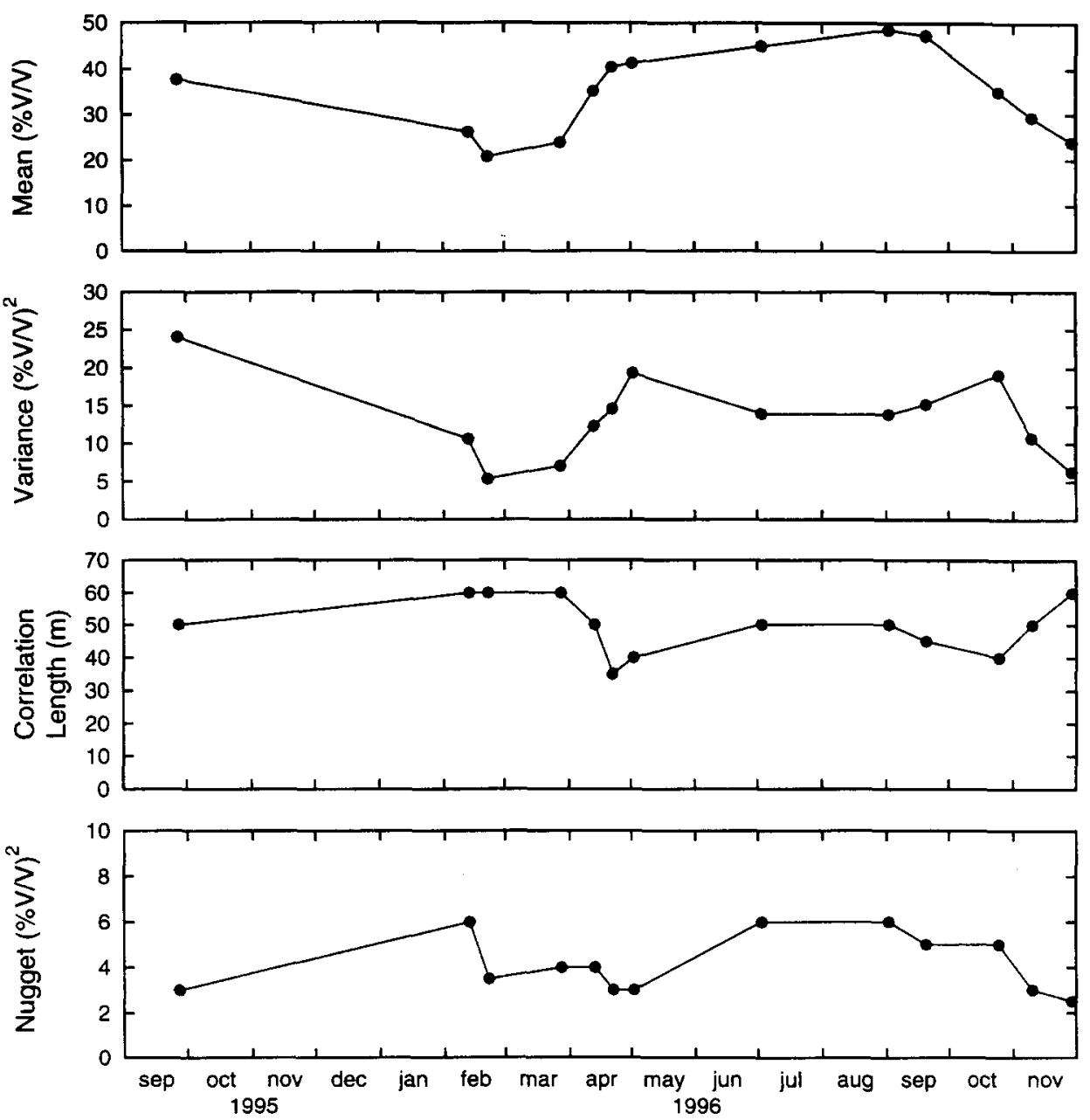

Fig. 6. The seasonal evolution of the geostatistical structure of the soil moisture pattern at Tarrawarra. The top graph shows the mean soil moisture, the second graph shows the spatial variance, the third graph shows the correlation length and the bottom graph shows the nugget.

radiative input to different slopes. In winter the sill is high due to the topographic control on soil moisture. The topographic control results from lateral redistribution of water under conditions of high soil moisture. This adds to the soil variability. There is a subtlety that occurs during the winter months wherein the variance drops slightly during the very wet periods (July through September) due to the effect of extensive saturation.

Correlation lengths vary between 35 and $60 \mathrm{~m}$ and are lowest $(35-50 \mathrm{~m})$ during the wet period and highest $(50-60 \mathrm{~m})$ during the dry periods. Again, these difference are explained on the basis of the processes controlling the soil moisture pattern. During summer the correlation lengths are high because moisture is uniform and the main impact on the moisture pattern is related to soils. In winter lateral redistribution leads to narrow wet strips within the drainage lines and hence small correlation lengths. Again there is a subtlety in winter wherein as the saturated areas expand during extremely wet conditions, there is a slight increase in the correlation length.

The nugget varies between 3 and $6(\% \mathrm{v} / \mathrm{v})^{2}$ (Figs. 5 and 6; Table 3). The variations in the nugget do not follow as consistent a seasonal pattern as either the sill or the correlation length, but there is a general tendency for higher nuggets during wetter conditions. 
The variation in the nugget is small compared to the variation in the sill, i.e. maximum nuggets are about twice the minimum nugget while maximum sills are about five times the minimum sill.

\subsection{Causes of the nugget effect}

All the sample variograms presented above show a clear nugget effect. There are two physical phenomena which can lead to a nugget effect in the data (see e.g. de Marsily, 1986, p. 304). First, a non-zero nugget can be due to random measurements errors. In this case, even if the samples are very closely spaced, there will be some variance between the measured data. Second, a non-zero nugget can be due to the fact that the data have not been collected at sufficiently small spacings to reveal the continuous behaviour of the phenomenon. This relates to subgrid variability which is variability at scales smaller than the sample spacing. If the nugget is due to the second reason it is sometimes called an "apparent nugget" (de Marsily, 1986). An apparent nugget will disappear if the data are collected at sufficiently small spacings.

Here, the physical reasons for the nugget in the variogram will be explored. As described above, a comparison of the TDR measurements with gravimetric measurements was conducted. The differences between the TDR and the gravimetric samples had a variance of $6.6(\% \mathrm{v} / \mathrm{v})^{2}$, based on 34 samples. Both the TDR and the gravimetric measurements have errors associated with them. Random errors in the TDR measurements exist due uncertainty in the determination of the dielectric constant from the TDR signal, variations due to slight differences in the insertion of the probes and possibly slight changes in the calibration with soil characteristics which vary across the catchment. Errors in the gravimetric measurements stem mainly from the determination of the sample volume. There will also be random errors introduced by slight differences in the sampling volume of the TDR and the gravimetric samples. Assuming half the $6.6(\% \mathrm{v} / \mathrm{v})^{2}$ variance is associated with each measurement method, one would expect a nugget of about $3(\% \mathrm{v} / \mathrm{v})^{2}$ variance due to random errors in the TDR measurements.

Most of the data sets used above have a minimum lag of $10 \mathrm{~m}$. There are two limiting possibilities for the behaviour of the variogram at scales smaller than the minimum lag. If all the variance at the minimum lag is due to measurement error, the variogram would remain constant at scales smaller than the minimum lag. If all the variance is attributable to subgrid variability (i.e. no random measurement error), the variogram would drop to $\gamma=0$ at $h=0$. Here the variograms have been extrapolated to $h=0$, based on the exponential model, to derive the nugget

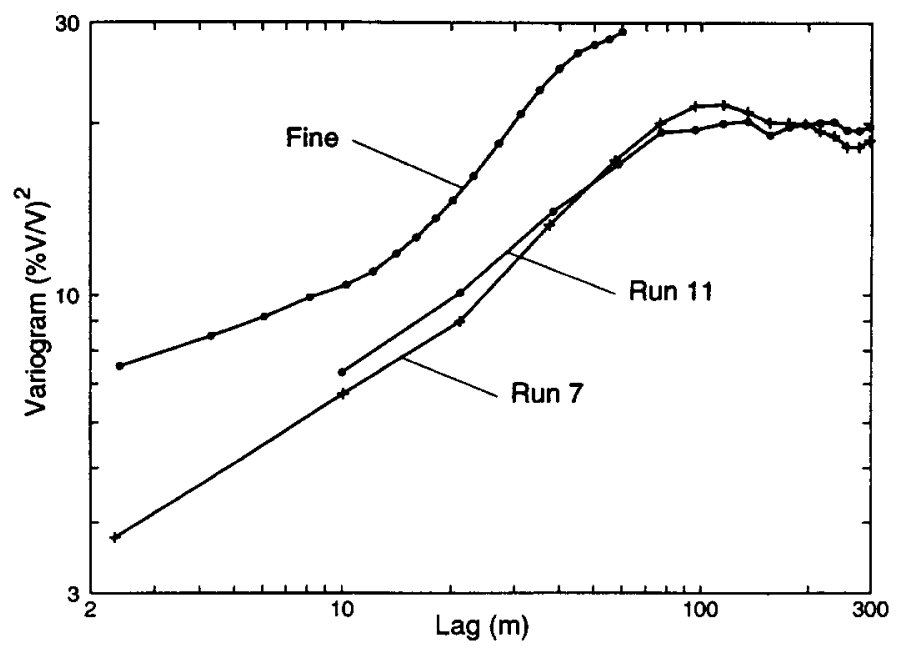

Fig. 7. Analysis of the small scale spatial correlations at Tarrawarra. The data from Run 7 (2 May 1996) were collected on four $10 \times 20 \mathrm{~m}$ grids offset by $2 \mathrm{~m}$ in an easterly and/or northerly direction. The data for the "fine" case were collected on a $2 \times 2 \mathrm{~m}$ grid from the eastern end of the catchment at the same time as data from Run 11 (25 October 1996). 
value. To examine the validity of the extrapolation, additional data are analysed. Fig. 7 examines the behaviour of the variogram at scales smaller than $10 \mathrm{~m}$ for two occasions. The first is Run 7, for which data were collected at the corners of a $2 \times$ $2 \mathrm{~m}$ square on a grid of $10 \times 20 \mathrm{~m}$. The variogram decreases from slightly less than $7(\% \mathrm{v} / \mathrm{v})^{2}$ to slightly less than $4(\% \mathrm{v} / \mathrm{v})^{2}$ as the lag decreases from 10 to $2 \mathrm{~m}$. The second is a fine scale set of 1734 moisture measurements collected on a $2 \times 2 \mathrm{~m}$ grid in the upper part of the eastern drainage line (Fig. 1) at the same time as Run 11. The fine scale data show a greater variance than Run 11 because they come from a highly variable part of the catchment. They also show that a significant reduction in variance from the $10 \mathrm{~m}$ scale in the remaining 11 data sets is partly due to small scale variability and partly to measurement error. This is consistent with the measurement error suggested above and supports the extrapolation of the fitted variograms to the nugget in Figs. 5 and 6 and Table 3.

\section{Effects of sample size}

An important issue is how the reliability of the variogram changes as the sample size changes. Here this is addressed in two stages, first using data from Run 7 and second by a subsampling analysis. During
Run 7 four soil moisture patterns, each containing 514 measurement points, were collected on $10 \times 20 \mathrm{~m}$ grids. These four patterns are offset by $2 \mathrm{~m}$ in an easterly and/or a northerly direction. The $10 \times 20 \mathrm{~m}$ grid is that used for the least detailed sampling runs. Fig. 8 shows variograms for the four patterns, plus that based on all 2056 points. The small scatter suggests that any one of the four patterns is representative of the true variogram. Thus the variogram based on the 500 measurements, which are the least detailed data sets presented above, are highly reliable.

Nearly always, variograms in the literature are estimated from data sets which are much smaller than the data sets used above (see Table 1). Therefore, an analysis of the change in reliability of the variogram with sample size was made. The methods used for this analysis are described above. Data from Run 3 and one of the four 514 point patterns of Run 7 were used and four cases were examined. These runs are representative of summer and winter conditions respectively. The cases consisted of 16 variograms based on 1 pair of transects, 8 variograms based on 2 pairs of transects, 4 variograms based on 4 pairs of transects, and 2 variograms based on 8 pairs of transects. Fig. 9 shows the results of this analysis. From the top row to the bottom row, variograms are based on $44,86,164$ and 296 points respectively. There is a large amount of scatter between the variograms based on one pair of transects (top graphs) and

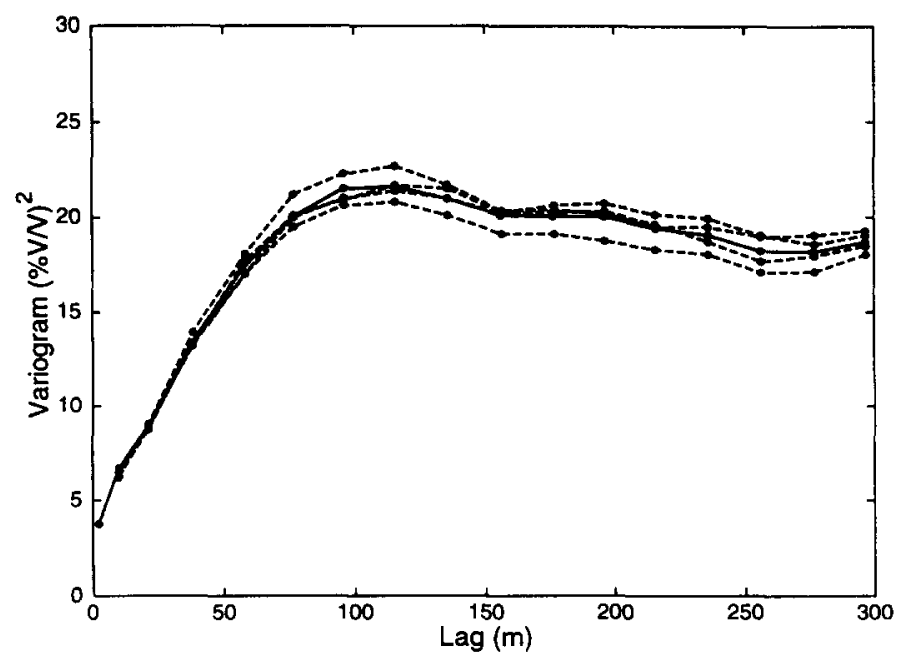

Fig. 8. Sample omnidirectional variograms for the four patterns of the $10 \times 20 \mathrm{~m}$ grid from Run 7 (514 samples each) plotted with the sample variogram based on all 2056 moisture measurements. 

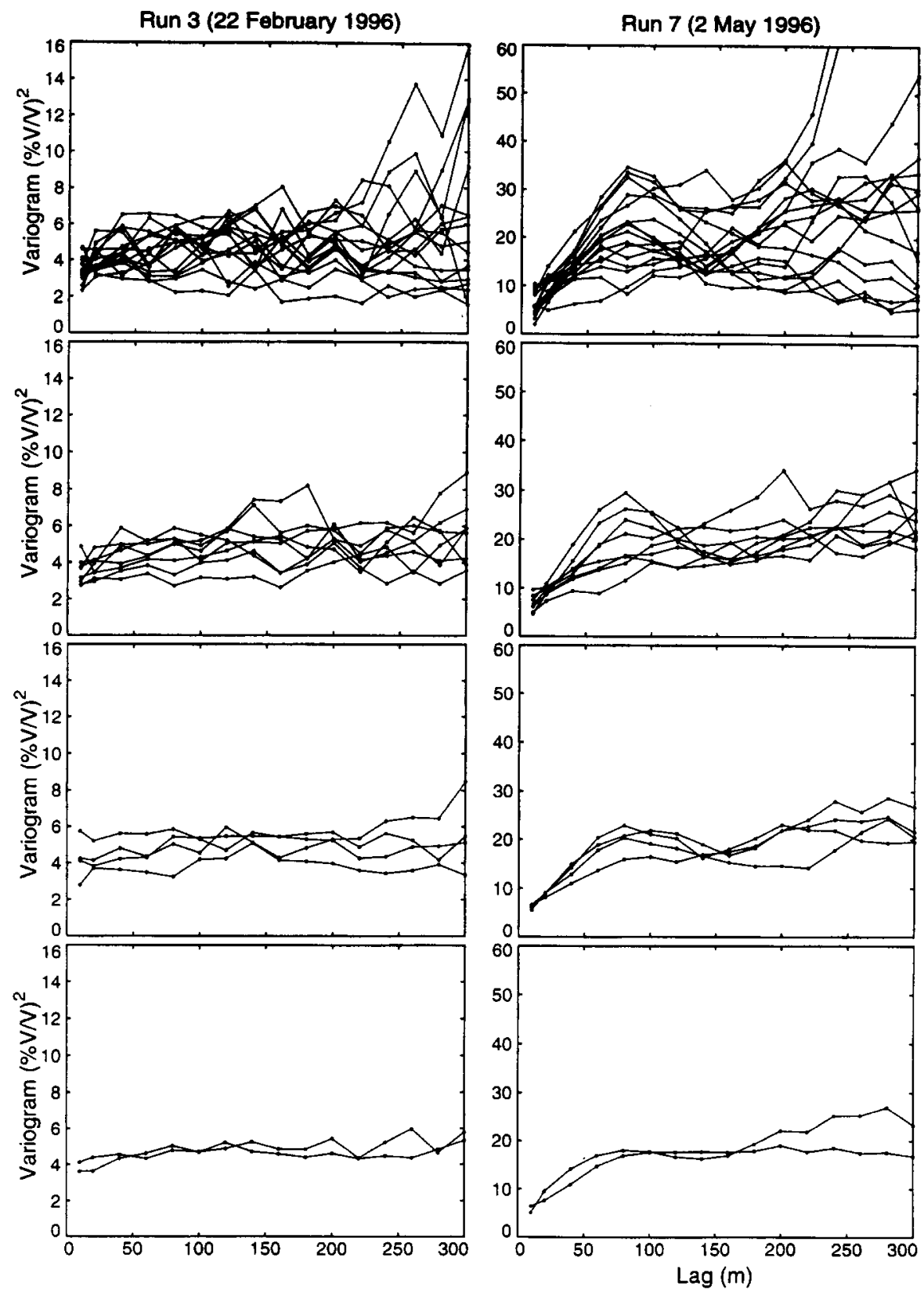

Fig. 9. The effect of sample size on the reliability of the variograms. Data from Tarrawarra on the 23 February 1996 (Run 3 ) and 2 May 1996 (Run 7) are used as an illustration. From the top to the bottom row, variograms are based on 44, 86, 164 and 296 points respectively.

individual variograms are very erratic. The sill varies by a factor of 3-4, it would be difficult to estimate a nugget and impossible to estimate a meaningful range. For this case, each variogram is typically based on 44 points (one pair of transects). Generally the scatter and irregularity of the variograms decreases as the sample size increases. The variograms based on 8 pairs of transects (about 300 points) are quite smooth and the two variograms are similar to each other. It would be possible to reliably estimate sills, nuggets 
and ranges for these variograms. These comparisons indicate that very detailed data sets are required to estimate reliably variogram parameters that are representative of the landscape.

\section{Discussion and conclusions}

Thirteen soil moisture patterns based on between 500 and 2000 TDR soil moisture measurements from the 10.5 ha Tarrawarra catchment in temperate southeastern Australia have been collected. The geostatistical structure of these soil moisture patterns has been analysed. The variograms are found to have a clear sill and a nugget. Exponential models including a nugget fit the sample variograms closely. The geostatistical structure is found to evolve seasonally. High sills $\left(15-25(\% \mathrm{v} / \mathrm{v})^{2}\right)$ and low correlation lengths $(35-50 \mathrm{~m})$ are observed during the wet winter period. During the dry summer period sills are smaller $\left(5-15(\% \mathrm{v} / \mathrm{v})^{2}\right)$ and correlation lengths are longer $(50-60 \mathrm{~m})$.

The seasonal changes in the geostatistical structure of soil moisture can be explained by the different processes controlling the soil moisture pattern. During summer, mean soil moisture is low due to high potential evapotranspiration as compared to precipitation. Also the spatial variance is low, i.e. soil moisture is uniform across the catchment. This is a consequence of the following processes. Lateral redistribution is small because unsaturated hydraulic conductivity is very small for low soil moisture. Also, because any available soil moisture will evaporate quickly, evapotranspiration is moisture limited and soil moisture is generally close to the wilting point. Since the wilting point is uniform across the catchment, soil moisture is also uniform. The uniformity results in low sills and high correlation lengths. Conversely, during winter, soil moisture is high, lateral redistribution is important and narrow wet strips exist in the drainage lines. These increase the variability and their small size decreases the correlation length. Both a nugget effect due to measurement error and variability at small scales contribute to the variability at the $10 \mathrm{~m}$ scale, which is the smallest scale in most the data sets.

The correlation lengths at Tarrawarra vary between 35 and $60 \mathrm{~m}$, implying practical ranges of 105 to $180 \mathrm{~m}$. When comparing the geostatistical parameters given in the literature with those observed at Tarrawarra, it is important to note that some of the values in the literature are highly uncertain due to relatively small sample sizes. It is quite likely that some of the ranges reported in the literature are representative of the sample only, but not of the landscape as a whole. Ranges reported by Whitaker (1993), Nyberg (1996) and evident from Loague (1992) are shorter than those at Tarrawarra, while those reported by Lehmann (1995) and Warrick et al. (1990) are longer. It is also interesting to note that there is a general tendency for data collected at larger spacings to have larger ranges. This means that, in addition to sampling uncertainties, part of the difference between values reported in the literature and those at Tarrawarra may be due to differences in the spacing of the samples (see Table 1). Part may also be due to differences in topography. For example, the Gårdsjön catchment (Nyberg, 1996) has shorter hillslope lengths than Tarrawarra. Clearly, differences in climate, soils and vegetation will also contribute to these differences.

Variogram sills reported by Lehmann (1995) and Nyberg (1996) are higher than those at Tarrawarra, while sills reported by Loague (1992) and Whitaker (1993) are lower. The factors contributing to these differences are probably similar to those contributing to the differences in the ranges.

At Tarrawarra, variogram sills (and spatial variances) are higher during wet conditions than during dry conditions. This is opposite to the seasonal pattern for moisture variance at Weiherbach reported by Lehmann (1995). A significant difference between Weiherbach and Tarrawarra is that permanently saturated zones exist at Weiherbach (B. Merz, pers. comm.) but not at Tarrawarra. At Tarrawarra the variance (sill) is smaller in summer than in winter because the catchment is uniformly dry during summer as discussed above. This is not the case at Weiherbach where a small part of the catchment is saturated while the rest of the catchment is relatively dry during summer. This large soil moisture range leads to a high variance. In winter at Weiherbach, the whole catchment is relatively wet and hence the variance is low.

In generalising the results found at Tarrawarra, it is important to recognise that landuse was uniform across the catchment. Multiple landuses are likely to 
increase soil moisture variability. Differences in landuse are likely to occur in larger catchments. Rainfall and geology will also become more variable at a large scale. Because the scale of variability of these controls tends to be large, it is likely that the correlation length of soil moisture would be slightly larger than for the Tarrawarra catchment.

The reliability of variograms based on different numbers of data points was analysed. Variograms for each of four patterns of 514 samples collected at the corners of a $2 \times 2 \mathrm{~m}$ square on a $10 \times 20 \mathrm{~m}$ grid demonstrate that the variograms used for the above structural analysis are highly reliable. An analysis based on transects subsampled from typical summer and winter soil moisture patterns showed that variograms based on 44 points are highly unreliable and that about 300 points are required to reliably estimate the sample variograms.

Of the studies summarised in Table 1, only five were based on more than 100 samples and only two were based on more than 200 samples. Neither of the studies with more than 200 samples explicitly considered spatial correlation structure. This is an important point when representing subgrid variability using spatial correlation structure in models, because it implies that the geostatistical structure derived from many commonly used sampling regimes may be quite unrepresentative of the true landscape variability. If results from geostatistical analyses are to be useful for interpolating soil moisture patterns from a few point data, deriving areal soil moisture averages or in distributed hydrologic modelling, they must be representative of the true spatial correlation structure of soil moisture in the landscape. This means that more detailed data sets than those generally available are required.

\section{Acknowledgements}

The Tarrawarra catchment is owned by the Cistercian Monks (Tarrawarra) who have provided free access to their land and willing cooperation throughout this project. Funding for the above work was provided by the Australian Research Council (project A39531077), the Cooperative Research Centre for Catchment Hydrology, and the Oesterreichische Nationalbank, Vienna (project 5309).
Garry Willgoose provided useful suggestions for this analysis. Reviewers are thanked for their comments.

\section{References}

Bell, K.R., Blanchard, B.J., Schmugge, T.J., Witczak, M.W., 1980. Analysis of surface moisture variations within large-field sites, Water Resour. Res., 16, 796-810.

Beven, K. and Kirkby, M.J., 1993. Channel Network Hydrology. Wiley, Chichester.

Blöschl, G., 1996. Scale and Scaling in Hydrology. Habilitationsschrift. Wiener Mitteilungen, Wasser-Abwasser-Gewässer, vol. 132, Inst. f. Hydraulik, Gewässerkunde und Wasserwirtschaft, Technical University of Vienna, Vienna, Austria.

Charpentier, M.A., Groffman, P.M., 1992. Soil moisture variability within remote sensing pixels, J. Geophys. Res., 97, 1898718995.

de Marsily, G., 1986. Quantitative Hydrogeology: Groundwater Hydrology for Engineers. Academic Press, San Diego, California, USA, pp. 440.

Entekhabi, D., Rodriguez-Iturbe, I., Castelli, F., 1996. Mutual interaction of soil moisture state and atmospheric processes, J. Hydrol., 184, 3-17.

Grayson, R.B., Western A.W., Chiew, F.H.S. and Blöschl, G. 1997. Preferred states in spatial soil moisture patterns: local and non-local controls. Water Resour. Res., 33(12), 28972908.

Hills, R.C., Reynolds, S.G., 1969. Illustrations of soil moisture variability in selected areas and plots of different sizes, J. Hydrol., 8, 27-47.

Hollenbeck, K.J., Schmugge, T.J., Hornberger, G.M., Wang, J.R., 1996. Identifying soil hydraulic heterogeneity by detection of relative change in passive microwave remote sensing observations, Water Resour. Res., 32, 139-148.

Isaaks, E.H. and Srivastava, R.M., 1989. An Introduction to Applied Geostatistics. Oxford University Press, New York, pp. 561 .

Jackson, T.J., Le Vine, D.E., 1996. Mapping surface soil moisture using an aircraft-based passive microwave instrument: algorithm and example, J. Hydrol., 184, 57-84.

Jenny, H., 1980. The Soil Resource. Springer, New York, pp. 377.

Journel, A.G. and Huijbregts, C.J., 1978. Mining Geostatistics. Academic Press, London, pp. 600.

Kitanidis, P.K., Bras, R.L., 1980. Real time forecasting with a conceptual hydrological model. 2. Applications and results, Water Resour. Res., 16, 1034-1044.

Lehmann, W., 1995. Anwendung geostatistischer Verfahren auf die Bodenfeuchte in ländlichen Einzugsgebieten. Institutsmitteilungen, vol. 52, Inst. f. Hydrologie und Wasserwirtschaft, Universität Karlsruhe, Karlsruhe.

Loague, K., 1992. Soil water content at R-5. Part 1. Spatial and temporal variability, J. Hydrol., 139, 233-251.

Moore, I.D., Burch, G.J., Mackenzie, D.H., 1988. Topographic effects on the distribution of surface soil water and the location 
of ephemeral gullies, Trans. Am. Soc. Agric. Eng.. 31, $1098-$ 1107.

Nyberg, L., 1996. Spatial variability of soil water content in the covered catchment at Gårdsjön, Sweden, Hydrological Process, $10,89-103$

Rajkai, K., Rydén, B.E., 1992. Measuring areal soil moisture distribution with the TDR method, Geoderma, 52, 73-85.

Rodríguez-Iturbe, I., Vogel, G.K., Rigon, R., Entekhabi, D., Castelli, F., Rinaldo, A., 1995. On the spatial organization of soil moisture fields, Geophys. Res. Lett., 22, 2757-2760.

Schmugge, T.J. and Jackson, T.J., 1996. Soil moisture variability. ln: J.B. Stewart, E.T., Engman, R.A. Feddes, Y. Kerr, (Editors), Scaling-up in Hydrology using Remote Sensing. Wiley, Chichester, pp. 183-192.

Warrick, A., Myers, D.E., 1987. Optimization of sampling locations for variogram calculations, Water Resour. Res., 23, $496-500$.
Warrick, A.W. Zhang, R., Moody, M.M. and Myers, D.E., 1990. Kriging versus alternative interpolators: errors and sensitivity to model inputs. In: K. Roth, H., Flühler, W.A. Jury, J.C. Parker (Editors), Fieldscale Water and Solute Flux in Soils. Birkhäser Verlage, Basel, pp. 157-164.

Western, A.W. and Grayson, R.B. The Tarrawarra data set: soil moisture patterns, soil characteristics and hydrological flux measurements. Water Resour. Res., submitted

Western, W.A., Grayson, R.B., Blöschl, G., Willgoose, G.R. and McMahon, T.A., 1997. Observed spatial organisation of soil moisture and its relation to terrain indices. Water Resour. Res., submitted.

Whitaker, M.P.L., 1993. Small-scale spatial variability of soil moisture and hydraulic conductivity in a semi-arid rangeland soil in Arizona. M. Sci. Thesis, University of Arizona. 